\title{
The Impact of Hydro-Priming and Osmo-Priming on Seedling Characteristics, Plant Hormone Concentrations, Activity of Selected Hydrolytic Enzymes, and Cell Wall and Phytate Hydrolysis in Sprouted Wheat (Triticum aestivum L.)
}

Elien Lemmens, ${ }^{*}{ }^{\dagger}$ Lomme J. Deleu, ${ }^{\dagger}$ Niels De Brier, ${ }^{\dagger} \|$ Wannes L. De Man, ${ }^{\dagger}$ Maurice De Proft, Els Prinsen, ${ }^{\S}$ and Jan A. Delcour ${ }^{\dagger}$

\footnotetext{
${ }^{\dagger}$ Laboratory of Food Chemistry and Biochemistry and Leuven Food Science and Nutrition Research Centre (LFoRCe), KU Leuven, Kasteelpark Arenberg 20, B-3001 Leuven, Belgium

${ }^{\star}$ Division of Crop Biotechnics, KU Leuven, 30014 Leuven, Belgium

${ }^{\S}$ Department of Biology, University of Antwerp, 2020 Antwerp, Belgium
}

Supporting Information

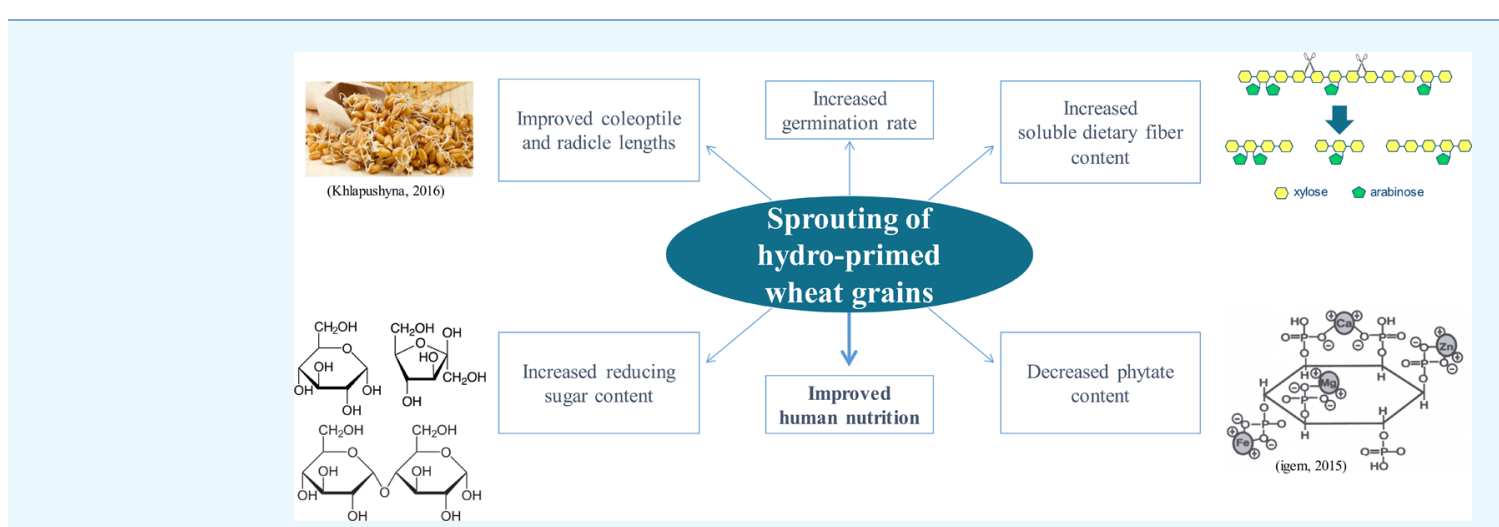

ABSTRACT: Priming improves the seed germination rate and grain yield. Before this work was executed, little, if any, research has been reported on priming wheat for improving its nutritional properties. The impact of hydro-priming and osmo-priming using solutions with different water potentials on selected hydrolytic enzyme activities and their breakdown of starch, cell wall materials, and phytates during subsequent sprouting was studied here. A higher germination rate in the early growth stage of seedlings was found for hydro-primed or osmo-primed $(-0.3,-0.6 \mathrm{MPa})$ grains. Hydro-primed sprouted grains had the longest radicles and coleoptiles and the highest hydrolytic enzyme activities. The latter lead to a $90 \%$ increase in reducing sugar, a $20 \%$ increase in water-extractable arabinoxylan, and an $8 \%$ decrease in phytate contents after 5 days of sprouting. This study thus offers opportunities for optimizing agricultural practice. The presence of different plant hormones and their concentrations are generally not affected by priming. However, the plant hormone concentrations in grains primed at $-1.2 \mathrm{MPa}$ and subsequently sprouted were lower than those in all other samples under study. The induction of too high osmotic stresses in these grains leads to disruption of the sprouting processes. Finally, it was for the first time found, based on the known biosynthesis pathways of wheat, that gibberellic acid (GA)20-oxidase in (primed) sprouted wheat is more active than GA3-oxidase and much more active than GA13-oxidase.

\section{INTRODUCTION}

Wheat (Triticum aestivum L.) germination initiates seedling growth and proceeds once adequate temperature and moisture content have been reached and dormancy is broken. Grains first need to absorb water to activate their metabolism and increase their respiration for embryo growth. ${ }^{1}$ During germination/sprouting of grains, three phases can be distinguished, which are related to the uptake of water. ${ }^{2}$ Phase I is characterized by rapid water uptake. This initiates the metabolism: DNA and mitochondria repair occur together with the synthesis of proteins using existing mRNA. During phase II, further water uptake is limited as the grain water potential is in near equilibrium with that of its surrounding environment. This phase is also called the activation or lag phase. In this phase, major metabolic changes take place, such as hydrolytic enzyme (for example $\alpha$-amylase, endoxylanase, and phytase) synthesis and other processes needed for embryo development. In phase III, a second rapid water uptake

Received: September 30, 2019

Accepted: November 25, 2019 
occurs. ${ }^{2,3}$ The radicle emerges, which is the so-called visible germination ${ }^{3}$ and is further referred to as sprouting. ${ }^{4}$

Germination/sprouting itself is regulated by plant hormones such as abscisic acid (ABA), gibberellic acid (GA), ethylene, auxins, cytokinins, and brassinosteroids. ${ }^{3,5}$ Their production and activity are controlled by the level of expression of relevant genes. The plant hormones most important for grain germination are $\mathrm{ABA}$ and GA. They are synthesized in the embryo and diffuse to the aleurone. GA triggers the aleurone cells to synthesize and secrete hydrolytic enzymes to mobilize grain reserves that fuel the germination while ABA counteracts these processes. ${ }^{1,6}$

As stated earlier, phase II of the germination process is important because of the major metabolic changes taking place therein. This phase is impacted by seed priming, a pre-sowing treatment. Briefly, grains are steeped in an osmotic solution to initiate metabolic activity and subsequently dried to their initial moisture content prior to sprouting/sowing. ${ }^{7}$ Common priming techniques include hydro-priming and osmo-priming.

Hydro-priming is a term covering grain imbibition with water for a limited time period $(7-14 \mathrm{~h})$. It initiates the above phase II metabolism without imposing a significant stress level on the grains. In the process, emergence of the radicle (phase III) is avoided by drying the grains to their original moisture content. $^{8}$

Osmo-priming is a controlled treatment bringing $\sim 10$ to $20 \%$ of full hydration. It allows phase II physiological and biochemical events to proceed by inducing abiotic stress conditions. In the process, emergence of the radicle (phase III) is avoided by the applied negative water potential. ${ }^{2,7,9,10}$

Osmo-priming is the most optimal at higher water potentials $(-0.3$ to $-1.5 \mathrm{MPa})$ and short priming times $(12 \mathrm{~h}$ to 2 days). ${ }^{9,11-13}$ When applying more negative water potentials and/or longer priming times, oxidative processes occur and so does a build-up of components detrimental to sprouting. ${ }^{14}$ Most frequently used as a solute for osmo-priming is highmolecular-weight polyethylene glycol (PEG). It induces high osmotic pressure and thereby modifies the availability of water in the germination medium. ${ }^{15}$ Indeed, the hydration rate is decelerated by the osmotic pressure. As a result, the level of cellular damage that normally occurs as a consequence of rapid water entry into dry grains is reduced. ${ }^{8}$ The use of PEG avoids toxicity during priming because it is not taken up by grains due to its high molecular weight. ${ }^{7}$ However, high PEG concentrations result in high viscosity, which in turn limits oxygen transfer and requires effective aeration during priming. ${ }^{16}$

Positive effects of priming on sprouting are ascribed to several phenomena. First, the increased water content that it causes is important for activating enzymes responsible for embryo development and mining of the starchy endosperm. ${ }^{17}$ Second, priming initiates biochemical mechanisms of cell repair, increases the RNA content, and enhances DNA replication. ${ }^{7,10,12,17}$ Third, priming appears to strengthen the defense system by increased activity of antioxidant enzymes such as superoxide dismutase, catalase, and glutathione reductase. ${ }^{7,18}$

Upon sowing, primed grains more rapidly absorb water and revive the grain metabolism than non-primed grains. ${ }^{15}$ As a result, seed priming increases the germination rate, ${ }^{19-21}$ uniformity of emergence, ${ }^{19,21}$ yield, ${ }^{21}$ and resistance of seedlings against unfavorable environmental conditions. ${ }^{20}$

This study is aimed to determine the impact of hydropriming and osmo-priming of wheat grains on the activities of selected hydrolytic enzymes involved in the breakdown of starch, cell wall materials, and phytates during subsequent sprouting. Amylases hydrolyze starch for the mobilization of sugars to the growing embryo. ${ }^{6}$ Endoxylanases are key enzymes in the breakdown of arabinoxylan (AX), the major component of wheat aleurone and starchy endosperm cell walls. ${ }^{22}$ Phytase activity during germination hydrolyzes phytate and therefore makes phosphate, mineral elements, and myo-inositol available for plant growth and development. ${ }^{23}$ Both are of interest in the context of increasing the bio-accessibility of mineral elements such as $\mathrm{Fe}$ and $\mathrm{Zn}$, which only amounts to $3-10 \%^{24}$ in mature wheat due to their entrapment in cells with rigid walls and their chelation by phytic acid. ${ }^{23,25}$

Overall, this work provides a framework for optimizing agricultural practice as well as the nutritional quality of wheatbased products. Also, the findings of the present study can be of interest to reduce process time in malt houses. Further, to the best of our knowledge, we are the first to report on the impact of hydro-priming and osmo-priming on energy mobilization and on plant hormone (GA, ABA, and auxin) production in activated wheat grains. Not only the active forms of the hormones but also some of their inactive conjugated storage forms were analyzed.

\section{RESULTS AND DISCUSSION}

2.1. Impact of Different Water Potentials of Priming on the Germination Percentage of Wheat. In the smallscale experiment, grains were allowed to sprout in PEG solutions of different water potentials $(0.0,-0.3,-0.6,-0.9$, -1.2 , or $-1.8 \mathrm{MPa}$ ) (see 3.2). After $72 \mathrm{~h}$ of sprouting at $21^{\circ} \mathrm{C}$, the moisture content in grains was lower when applying lower water potentials during priming (Table 1). They amounted to

Table 1. Moisture Contents (\%) and Germination Percentages (\%) in Hydro-Primed (0.0 $\mathrm{MPa})$ and OsmoPrimed $(-0.3,-0.6,-0.9,-1.2$, and $-1.8 \mathrm{MPa})$ Wheat Grains after $72 \mathrm{~h}$ of Sprouting at $21{ }^{\circ} \mathrm{C}$ (see Small-Scale Experiment)

$\begin{array}{rcc}\text { water potential } & \text { moisture content (\%) } & \text { germination percentage (\%) } \\ 0.0 \mathrm{MPa} & 56 & 96 \\ -0.3 \mathrm{MPa} & 45 & 92 \\ -0.6 \mathrm{MPa} & 39 & 80 \\ -0.9 \mathrm{MPa} & 37 & 28 \\ -1.2 \mathrm{MPa} & 35 & 0 \\ -1.8 \mathrm{MPa} & 33 & 0\end{array}$

$56 \%$ when priming was with deionized water $(0.0 \mathrm{MPa}$, hydropriming) and 45 and $33 \%$ when osmo-priming was with the -0.3 and $-1.8 \mathrm{MPa}$ PEG solutions, respectively. Thus, an applied water potential of $-0.3 \mathrm{MPa}$ already strongly impacted the water uptake rate. This may be due to the smaller differences in water potential between medium and grain when using PEG solutions than when using deionized water, which made water uptake more difficult in the former.

The lower moisture content of the osmo-primed grains led to slower germination/sprouting. After $72 \mathrm{~h}$ at $21{ }^{\circ} \mathrm{C}$, the germination percentage was $96 \%$ in hydro-primed grains and 92 and $80 \%$ in grains primed at -0.3 and $-0.6 \mathrm{MPa}$, respectively (Table 1$)$. In addition, hydro-priming and osmopriming at -0.3 and $-0.6 \mathrm{MPa}$ were suitable pretreatments as the grains were in phase II of the germination process for a relative long time period. Indeed, radicle emergence was only 
observed after $24 \mathrm{~h}$ (data not shown). Applying even lower water potentials $(-0.9,-1.2$, and $-1.8 \mathrm{MPa})$ led to germination percentages of maximally $28 \%$. The grains were imposed to high osmotic stress during the entire time of sprouting $(72 \mathrm{~h})$. Earlier, Abbasdokht ${ }^{26}$ noted germination percentages of only 36 and $27 \%$ for wheat grains osmo-primed with PEG solutions of -0.8 and $-1.2 \mathrm{MPa}$, respectively, and sprouted for at least 5 days at $25{ }^{\circ} \mathrm{C}$. Further, Almansouri et al. ${ }^{27}$ observed no seedling growth (i.e., a germination percentage of $0 \%$ ) in wheat grains osmo-primed in PEG solution of $-1.6 \mathrm{MPa}$ after 6 days at $24{ }^{\circ} \mathrm{C}$. The reduced germination/sprouting ability as a result of increased PEG concentrations during priming may result from inhibition of the grain metabolism as a result of the high abiotic stress. ${ }^{28}$

Based on these results, for further experiments, we selected hydro-priming and osmo-priming at -0.3 and $-0.6 \mathrm{MPa}$ as valuable water potentials and at $-1.2 \mathrm{MPa}$ as a too extreme (toxic) treatment, the latter for comparison reasons. Similar germination percentages and radicle and coleoptile lengths were observed at priming times of 8,12 , or $16 \mathrm{~h}$ (data not shown).

2.2. Impact of Hydro-Priming and Osmo-Priming on Seedling Characteristics of Sprouted Wheat. We observed no significantly different increases in moisture content during steeping and sprouting in the pilot-scale micro malting system at $15{ }^{\circ} \mathrm{C}$ between control (i.e., regular, untreated wheat) and hydro-primed and osmo-primed wheat grains (data not shown). This was rather surprising as osmopriming was expected to increase the uptake of water during steeping due to the lower water potential in these grains than in control wheat. Indeed, grains release organic solutes such as free amino acids (for example, proline and glycine) and betaine in response to the low external water potential during osmopriming. ${ }^{29}$

2.2.1. Germination Percentage. The impact of different priming treatments on the germination rate and capacity of wheat grains was determined by monitoring the percentage of germinated grains at specific times during the steeping phase of $29 \mathrm{~h}$ and after $24 \mathrm{~h}$ of sprouting (Figure 1 ). The first visible sign of sprouting was observed after $15 \mathrm{~h}$ of steeping. Between 15 and $29 \mathrm{~h}$ of steeping, the hydro-primed and osmo-primed

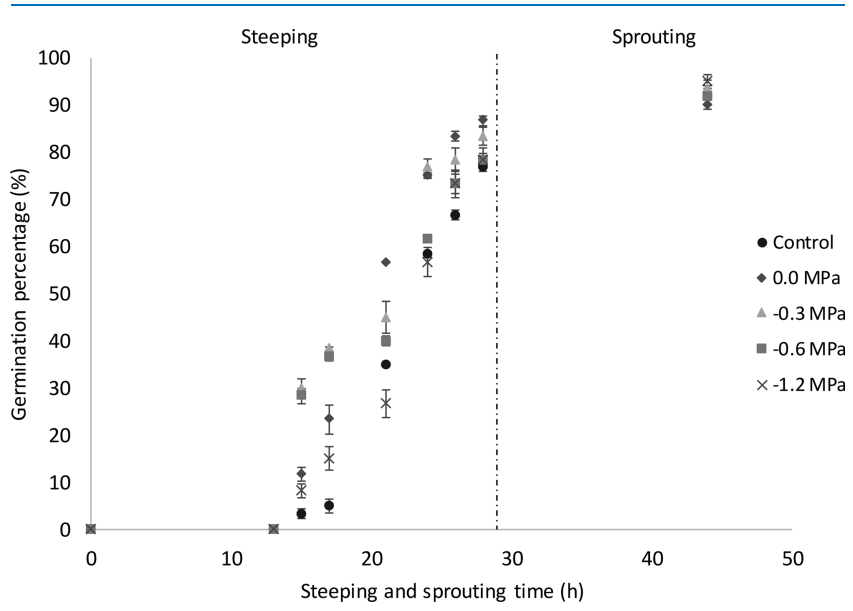

Figure 1. Germination percentages (\%) as a function of steeping and sprouting time $(\mathrm{h})$ of non-primed (control), hydro-primed (0.0 $\mathrm{MPa})$, and osmo-primed $(-0.3,-0.6$ and $-1.2 \mathrm{MPa})$ wheat grains (see pilot-scale experiment). wheat grains had higher germination percentages than the control except when priming was at $-1.2 \mathrm{MPa}$. The wheat grains primed at -0.3 and $-0.6 \mathrm{MPa}$ had the highest germination percentages after 15 and $20 \mathrm{~h}$ of steeping, which clearly shows the beneficial effect of osmo-priming already early in the process. The increased germination after osmopriming at -0.3 and $-0.6 \mathrm{MPa}$ can be ascribed to an increased rate of cell division in the grain ${ }^{11}$ and the completion of pregerminative metabolic activities and repair processes. All the above treatments make the primed grains sooner ready for radicle protrusion than control grains.' Later during the process (20-29 h of steeping), clearly higher germination percentages were noted for the hydro-primed grains and grains primed at $-0.3 \mathrm{MPa}$ than for control grains. In contrast, similar germination percentages were noted for both control grains and grains primed at -0.6 and $-1.2 \mathrm{MPa}$.

After $24 \mathrm{~h}$ of sprouting at $15{ }^{\circ} \mathrm{C}$, at least $90 \%$ of all primed and control wheat samples had germinated. Earlier, Almansouri et al. $^{27}$ stated that PEG-treated wheat embryos remain quiescent and that almost all of them can sprout when the stress imposed by osmo-priming is relieved. The obtained results here are different from the results in the small-scale experiment (see 2.1) where the osmotic stress was not relieved during sprouting of wheat.

2.2.2. Radicle and Coleoptile Length. The lengths of both radicles and coleoptiles were measured after 24, 72, and $120 \mathrm{~h}$ of sprouting (Figure 2). When comparing the impact of
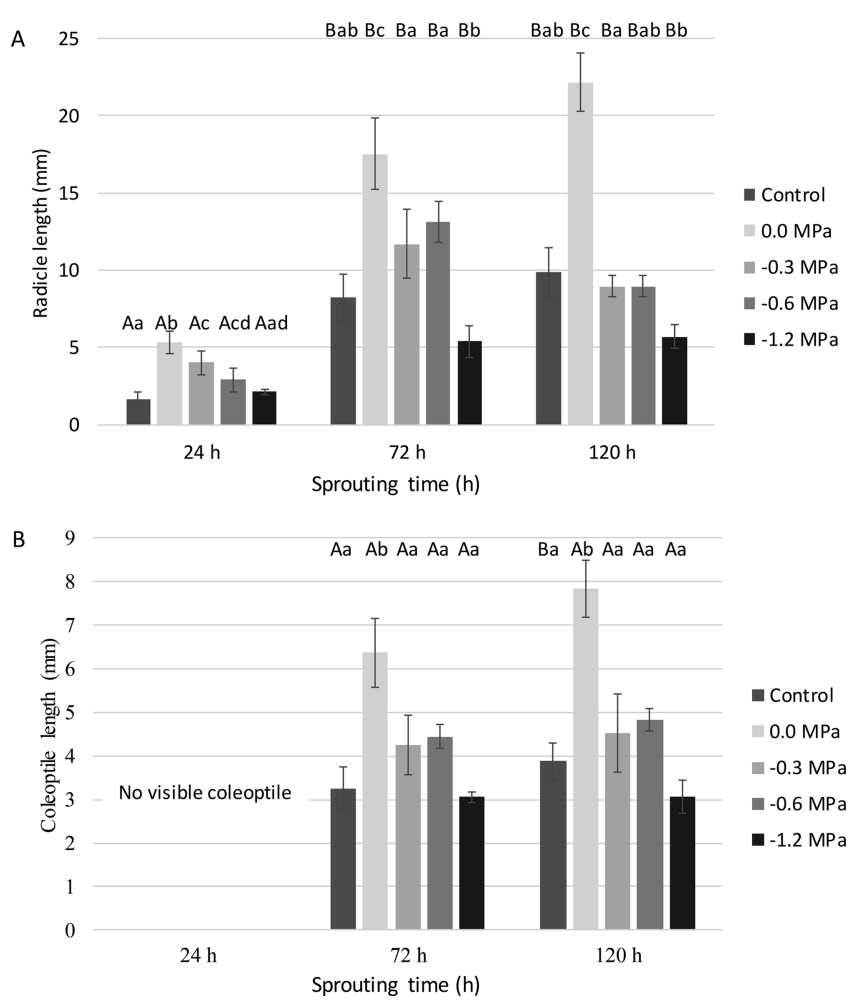

Figure 2. (A) Radicle lengths ( $\mathrm{mm}$ ) and (B) coleoptile lengths (mm) as a function of sprouting time (h) of non-primed (control), hydroprimed $(0.0 \mathrm{MPa})$, and osmo-primed $(-0.3,-0.6$, and $-1.2 \mathrm{MPa})$ wheat grains (see pilot-scale experiment). Mean values for the same treatment differ significantly $(P<0.05)$ with those not sharing the same upper case letter. Mean values for the same sprouting time differ significantly $(P<0.05)$ with those not sharing the same lower case letter. 
A

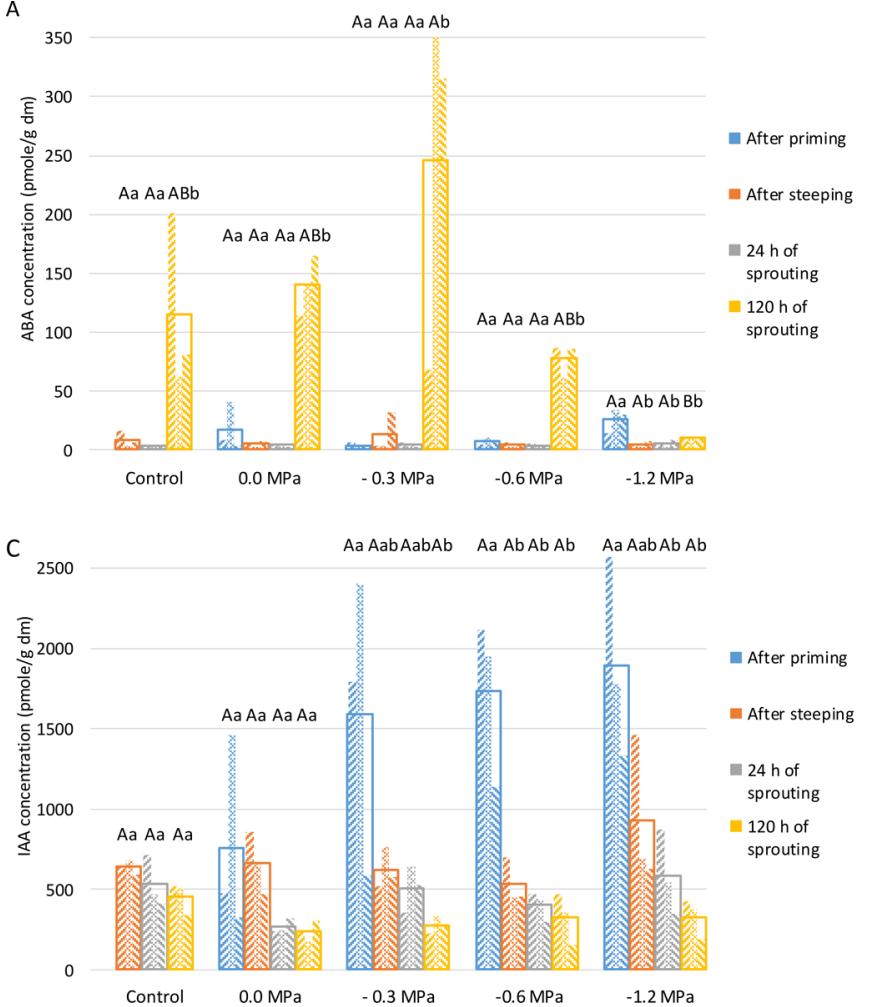

B
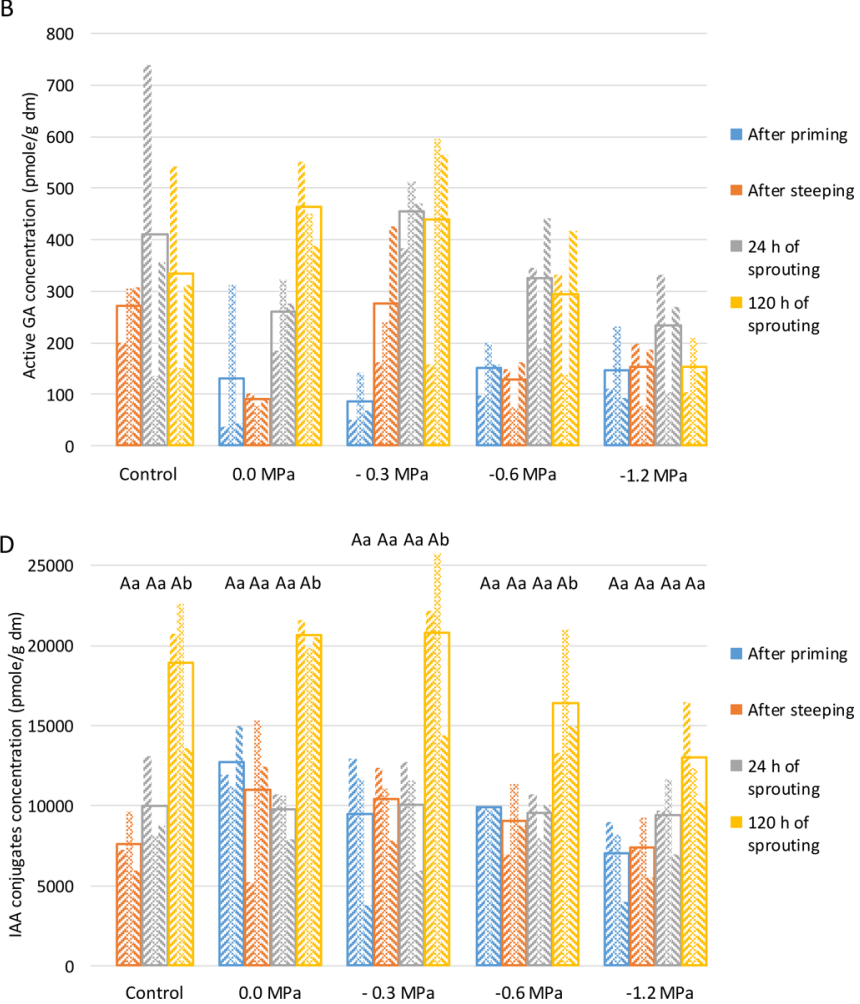

Figure 3. Plant hormone [(A) abscisic acid (ABA), sum of present (B) active gibberellic acid (GA) forms, (C) indole acetic acid (IAA), and (D) IAA conjugates] concentrations $[\mathrm{pmol} / \mathrm{g}$ dry matter $(\mathrm{dm})]$ for different sample types [control wheat, hydro-primed wheat $(0.0 \mathrm{MPa})$, and osmoprimed wheat $(-0.3,-0.6$, and $-1.2 \mathrm{MPa})]$ after priming, steeping $\left(0 \mathrm{~h}\right.$ of sprouting), and 24 and $120 \mathrm{~h}$ of sprouting at $15{ }^{\circ} \mathrm{C}(\mathrm{see}$ pilot-scale experiment). Values of replicates are represented as three small columns within an unfilled column giving the mean value of these three replicates. Mean values for the same process time differ significantly $(P<0.05)$ with those not sharing the same upper case letter. Mean values for the same sample type differ significantly $(P<0.05)$ with those not sharing the same lower case letter.

different priming treatments at a same sprouting time $(24 \mathrm{~h})$, it was observed that mild priming $(0.0,-0.3$, and $-0.6 \mathrm{MPa})$ resulted in increased radicle growth (Figure $2 \mathrm{~A}$ ). While no coleoptiles were visible yet (Figure 2B), radicles were approximately 3 times longer in hydro-primed (0.0 $\mathrm{MPa})$ grains and 1.8 to 2.5 times longer in grains primed at -0.3 and $-0.6 \mathrm{MPa}$ than in control wheat. This result is in line with that of Yari et al. ${ }^{13}$ who found maximum radicle and coleoptile lengths in wheat grains primed with PEG solutions of approximately -0.15 or approximately $-0.54 \mathrm{MPa}$ for $12 \mathrm{~h}$ at $20{ }^{\circ} \mathrm{C}$ and subsequently sprouted for 8 days at $25{ }^{\circ} \mathrm{C}$. The radicle and coleoptiles in their primed grains were $6-10 \%$ longer than those in control grains. ${ }^{13}$ Increased coleoptile and radicle lengths as a result of priming may be due to increased nuclear replication in these tissues. ${ }^{12}$ In addition, Zhang et al. ${ }^{18}$ showed that improved cell membrane stability and reduced lipid peroxidation in seedlings of sorghum grains osmo-primed with PEG solution of approximately $-0.56 \mathrm{MPa}$ are accompanied by increased activities of antioxidant enzymes such as superoxide dismutase, catalase, and glutathione reductase. This suggests that grain priming improves plant growth by reducing the impact of oxidative reactions caused by reactive oxygen species in plant cells. ${ }^{18}$ Finally, it is hypothesized that the seedlings of primed wheat may contain higher potassium, zinc, and/or calcium contents than those of control wheat as these mineral elements are involved in cell growth, ${ }^{30}$ cell elongation, ${ }^{31}$ and/or cell division ${ }^{31}$ and as Lemmens et ll. $^{32}$ found them to be present in elongating coleoptile and/or radicle tips of wheat.
After 72 and $120 \mathrm{~h}$ of sprouting, only the hydro-primed grains had significantly longer radicles and coleoptiles (doubled lengths) than control grains. Abbasdokht ${ }^{26}$ found the radicles and coleoptiles of wheat grains subjected to hydropriming to be 1.2- to 1.3-fold longer than those of their nonprimed counterparts. Furthermore, others noted that hydropriming is more effective at improving the germination rate and increasing radicle and coleoptile lengths in wheat than priming treatments with $\mathrm{PEG},{ }^{13,21}$ potassium phosphate, ${ }^{13,21}$ calcium chloride, ${ }^{10}$ and potassium chloride. ${ }^{10,13,21}$

As a note, significant differences were observed neither in radicle nor in coleoptile lengths between 72 and $120 \mathrm{~h}$ of sprouting within the same priming treatment. This may be because no additional submersion in water was performed during sprouting.

2.3. Impact of Hydro-Priming and Osmo-Priming on Plant Hormone Concentrations in (Sprouted) Wheat. To evaluate the impact of different priming treatments on the presence of plant hormones in wheat grains during subsequent steeping and sprouting, concentrations of $\mathrm{ABA}$, active GAs, inactive GAs, IAA (conjugates), IAA-OX (conjugates), IAA$\mathrm{OH}$ (conjugates), IBA-OX (conjugates), and IBA-OH (conjugates) were determined. As a note, the oxidized forms of IAA were hardly present in all wheat samples (data not shown).

The ABA concentration after priming and during the first 24 $\mathrm{h}$ of sprouting was low in all samples $(<41 \mathrm{pmol} / \mathrm{g} \mathrm{dm})$ (Figure 3A). This was probably due to the presence of $A B A$ as a biologically inactive metabolite. ${ }^{33}$ Only low levels of ABA 


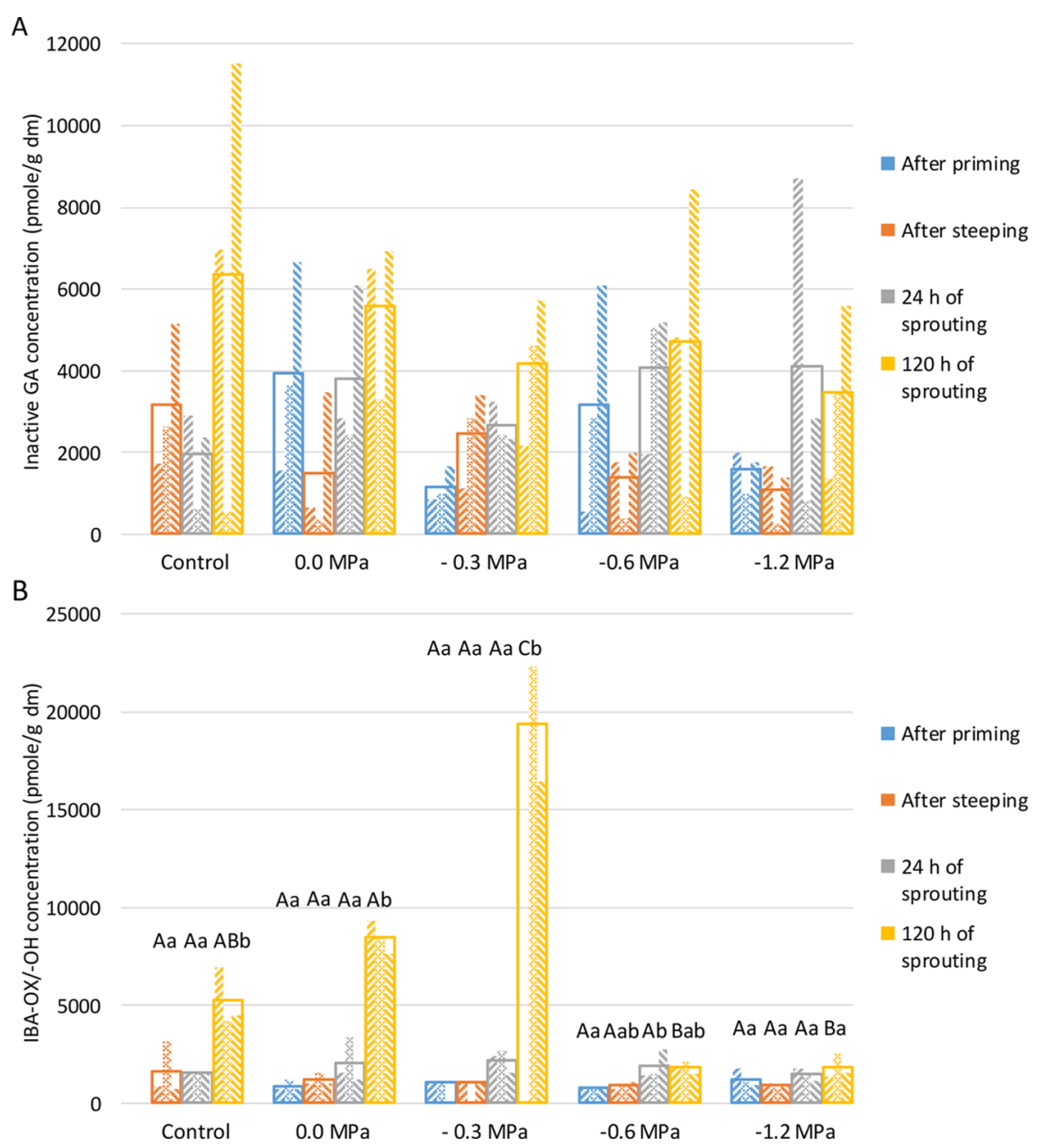

Figure 4. Plant hormone [(A) sum of inactive gibberellic acid (GA) forms and (B) sum of indole butyric acid (IBA)-OH and IBA-OX] concentrations $[\mathrm{pmol} / \mathrm{g}$ dry matter $(\mathrm{dm})]$ for different sample types [control wheat, hydro-primed $(0.0 \mathrm{MPa})$, and osmo-primed $(-0.3,-0.6$, and $-1.2 \mathrm{MPa})$ ] wheat after priming, steeping $\left(0 \mathrm{~h}\right.$ of sprouting), and 24 and $120 \mathrm{~h}$ of sprouting at $15{ }^{\circ} \mathrm{C}$ (see pilot-scale experiment). Values of replicates are represented as small columns within an unfilled column giving the mean value of these replicates. Mean values for the same process time differ significantly $(P<0.05)$ with those not sharing the same upper case letter. Mean values for the same sample type differ significantly $(P<$ 0.05 ) with those not sharing the same lower case letter.

allow for seedling development since $\mathrm{ABA}$ adversely affects grain germination. ${ }^{5} \mathrm{ABA}$ concentrations in all samples but the one primed at $-1.2 \mathrm{MPa}$ were increased after $120 \mathrm{~h}$ of sprouting with levels ranging between 75 and $250 \mathrm{pmol} / \mathrm{g} \mathrm{dm}$, which inter alia protected the growing seedling from dehydration. A major role of $\mathrm{ABA}$ during vegetative growth is to optimize growth under adverse conditions by maintaining osmotic homeostasis. ${ }^{34}$ Yamada ${ }^{35}$ found that endogenous ABA levels decrease during steeping of barley, while especially in the later stage of sprouting (4-6 days of sprouting), they increase.

$\mathrm{ABA}$ is positively related to activities of plants under stress. ${ }^{5}$ At the cellular level, it can indeed promote the tolerance to some abiotic stresses such as those imposed by low temperature, salinity, and drought. ${ }^{34}$ That ABA levels in grains primed at $-1.2 \mathrm{MPa}$ remained low during sprouting might be related to induction of too high osmotic stresses in these grains.

GA is needed for grain germination. It inhibits ABA activity and activates catabolizing enzymes such as amylases and peptidases. ${ }^{5,34}$ Moreover, it may benefit the growth of the embryo and overcome the mechanical restraint for radicle protrusion by weakening the tissues surrounding it. ${ }^{36}$ Given the above, one would expect that, in line with it having long radicles and coleoptiles (see 2.2.2) and increased $\alpha$-amylase activity levels (see 2.4), hydro-primed wheat has clearly higher levels of active (Figure 3B) and/or inactive GA than control wheat (Figure 4A). However, this could not be concluded from the present data since no significant differences in GA concentrations were found between the different samples under study. Plant hormone concentrations are subject to biological variation and strongly depend on the exact moment of sampling since their upregulation and downregulation are dynamic processes, certainly when considering eight different GA types at low concentrations.

In all wheat samples, GA7 was the active form present at the highest concentrations $(10-650 \mathrm{pmol} / \mathrm{g} \mathrm{dm})$ followed by GA4 $(2-150 \mathrm{pmol} / \mathrm{g} \mathrm{dm})$. GA12, GA15, GA9, and GA44 were the dominant inactive GA forms present in all wheat samples. GA12 (levels ranging between 160 and $6400 \mathrm{pmol} / \mathrm{g} \mathrm{dm}$ ) and GA15 (levels ranging between 74 and $5700 \mathrm{pmol} / \mathrm{g} \mathrm{dm}$ ) were dominantly present in control and primed (sprouted) wheat grains, while GA9 was present at intermediate concentrations (30-1300 pmol/g dm) and GA44 was present at rather low $(25-600 \mathrm{pmol} / \mathrm{g} \mathrm{dm})$ concentrations. The active form GA1 and the inactive form GA19 were detected at levels very near the limit of quantification $(41 \pm 19$ and $33 \pm 16 \mathrm{pmol} / \mathrm{g} \mathrm{dm}$, 
respectively) in 47 and $35 \%$ of all samples measured, respectively.

These observations match well with the known biosynthesis pathways of wheat GAs in which different forms are derived from geranylgeranyl diphosphate as a substrate through a series of oxidation and hydroxylation reactions. ${ }^{37-39}$ From GA12 aldehyde, GA15 and GA9 arise by GA20-oxidase action. The active forms GA7 and GA4 arise from GA9 by GA3-oxidase action. GA44, GA19, and GA1 can only be formed by a step in which GA13-oxidase is active ${ }^{39}$ (Figure S1, Supporting Information). Our results are thus the first to lead to the suggestion that GA20-oxidase during wheat germination/ sprouting is more active than GA3-oxidase and much more active than GA13-oxidase.

Auxins like IAA and IBA play a key role in regulating cell cycling, growth, elongation, and development and are, for example, present in the grain radicle tip during and after grain sprouting. ${ }^{5}$ Priming of grains prior to sprouting did not impact their IAA concentrations. Indeed, for a given process time, no significant differences were found between the different sample types (Figure 3C). While osmo-priming led to significantly higher IAA concentrations after priming, it did not result in higher levels during subsequent sprouting. The latter may indicate the biosynthesis of radicle and/or coleoptile apical meristematic tissues during osmo-priming.

Priming of grains prior to sprouting also did not impact the concentrations of their IAA conjugates (Figure 3D). Only after $120 \mathrm{~h}$ of sprouting were significantly higher IAA conjugate concentrations found in all sample types except grains primed at $-1.2 \mathrm{MPa}$.

Further, the IAA concentrations generally decreased while the IAA conjugate concentrations increased during sprouting. The imbalance between active IAA and inactive IAA conjugates is a result of intensive regulation of the hormone steady state during seedling development, and we postulate that, when the germination process is activated and the seedling is growing (i.e., sprouting), IAA is less needed, leading to its conversion into its conjugates. The sum of IBA-OH and IBA-OX (IBA-OX/-OH) concentrations (Figure 4B) was $\sim 10$ fold higher than the IAA concentrations. Moreover, the IBA$\mathrm{OX} /-\mathrm{OH}$ and the IAA conjugate concentrations followed a similar trend in primed, steeped, or sprouted wheat grains. IBA can be oxidized to IBA-OX/-OH and the latter into IAA. ${ }^{40}$ IBA has been considered to be an endogenous auxin in a variety of plant species. It may be more important than IAA in radicle initiation and development since it is for example more stable under various light and temperature conditions and less susceptible to enzymatic hydrolysis. It may function in vivo through its conversion to IAA or act as an independent auxin. 41

Finally we note that, overall, the plant hormone concentrations in grains primed at $-1.2 \mathrm{MPa}$ and subsequently sprouted were lower than in all other samples under study. The high osmotic stress to which these grains were subjected may have impacted their hormone balance and/or transport.

2.4. Impact of Hydro-Priming and Osmo-Priming on $\alpha$-Amylase Activity Levels and Reducing Sugar Contents in (Sprouted) Wheat. The $\alpha$-amylase activity in nonsprouted control wheat was low. It amounted to only $4.5 \mathrm{U} / \mathrm{h} /$ $\mathrm{g} \mathrm{dm}$. A huge increase was observed in control and primed grains as a result of $120 \mathrm{~h}$ of sprouting (Figure 5A). Germination/sprouting initiates de novo synthesis of $\alpha$ amylase. $^{42}$ After steeping (i.e., $0 \mathrm{~h}$ of sprouting), its activity
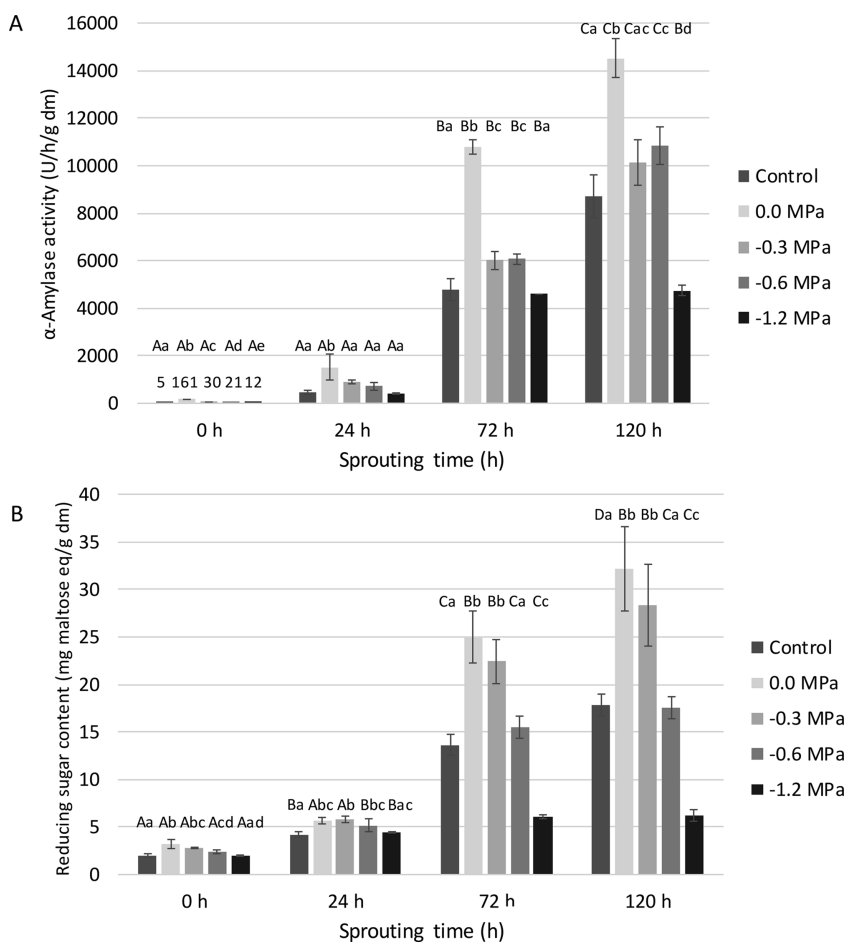

Figure 5. (A) $\alpha$-Amylase activity levels $[\mathrm{U} / \mathrm{h} / \mathrm{g}$ dry matter $(\mathrm{dm})]$ and (B) reducing sugar contents [mg maltose equivalents (eq)/g dm] as a function of sprouting time $(\mathrm{h})$ of non-primed (control), hydroprimed $(0.0 \mathrm{MPa})$, and osmo-primed $(-0.3,-0.6$ and $-1.2 \mathrm{MPa})$ wheat grains (see pilot-scale experiment). Mean values for the same treatment differ significantly $(P<0.05)$ with those not sharing the same upper case letter. Mean values for the same sprouting time differ significantly $(P<0.05)$ with those not sharing the same lower case letter.

in primed wheat was significantly higher than that in control wheat. This was expected as priming activates the metabolism, leading to faster induction of germination/sprouting processes such as the mobilization of starch to supply energy for the embryo. ${ }^{7}$ During subsequent sprouting, mainly hydro-primed grains showed clearly 2- to 3-fold higher enzyme activity levels, which goes well with the observation of significantly longer radicles and coleoptiles (see 2.2.2). Earlier, Jafar et al. ${ }^{43}$ noted an only $30 \%$ higher increase in $\alpha$-amylase activity in hydroprimed wheat. No significant difference in enzyme activity was observed after 72 versus $120 \mathrm{~h}$ of sprouting for grains primed at $-1.2 \mathrm{MPa}$. The high PEG concentration induced osmotic stress in these grains and led to disruption of the sprouting processes which was also clear from their low plant hormone concentrations (see 2.3).

The reducing sugar content in non-sprouted control wheat amounted to $1.5 \mathrm{mg}$ maltose eq/g dm. Sprouting wheat for $120 \mathrm{~h}$ led to a 4 - to 20 -fold increase in the reducing sugar content depending on the priming treatment and in line with the $\alpha$-amylase activity levels (Figure 5B). $\alpha$-Amylase action leads to (partial) hydrolysis of starch into maltose, maltotriose, and a wide range of dextrins and thus increases the reducing sugar content. ${ }^{42}$ In this context, it is worth mentioning that Farooq et al. ${ }^{44}$ revealed a direct relationship between increased $\alpha$-amylase activity levels and total soluble sugar contents in hydro-primed rice grains.

In the present case, the largest increase in enzymatic activity and formation of reducing sugars was observed between 24 
and $72 \mathrm{~h}$ of sprouting (Figure 5). The reducing sugar contents in (primed) sprouted wheat grains strongly depended on the pretreatment. Hydro-priming and osmo-priming at $-0.3 \mathrm{MPa}$ led to significantly higher reducing sugar contents during sprouting, especially after 72 and $120 \mathrm{~h}$. This can lower the need for sugar addition in wheat-derived products and is also of interest in the context of brewing in which high concentrations of fermentable sugars are needed.

The concentrations in the sprouted primed grains amounted to 25-32 $\mathrm{mg}$ maltose eq/g dm after hydro-priming and to 22$28 \mathrm{mg}$ maltose eq $/ \mathrm{g} \mathrm{dm}$ after osmo-priming $(-0.3 \mathrm{MPa})$, while values of only $14-18 \mathrm{mg}$ maltose $\mathrm{eq} / \mathrm{g} \mathrm{dm}$ were found in control wheat. There was no clear difference between the reducing sugar content as a result of sprouting between control grains and that of grains primed at $-0.6 \mathrm{MPa}$. However, priming at $-1.2 \mathrm{MPa}$ clearly inhibited $\alpha$-amylase activity, which was reflected in low reducing sugar contents, which only amounted to $6.2 \mathrm{mg}$ maltose $\mathrm{eq} / \mathrm{g} \mathrm{dm}$ in $120 \mathrm{~h}$ sprouted wheat grains.

2.5. Impact of Hydro-Priming and Osmo-Priming on Endoxylanase Activity Levels and Water-Extractable Arabinoxylan Contents in (Sprouted) Wheat. The endoxylanase activity level in non-sprouted control wheat was $0.13 \mathrm{U} / \mathrm{h} / \mathrm{g} \mathrm{dm}$. Significant differences were only observed after $72 \mathrm{~h}$ of sprouting. De Backer et al. ${ }^{22}$ also observed low endogenous endoxylanase activities in wheat in the early stage of sprouting (up to $72 \mathrm{~h}$ ). In the present case, after $72 \mathrm{~h}$ of sprouting, hydro-primed grains had much higher activity levels $(2.1 \mathrm{U} / \mathrm{h} / \mathrm{g} \mathrm{dm})$ than osmo-primed $(1.1 \mathrm{U} / \mathrm{h} / \mathrm{g} \mathrm{dm}$ for -0.3 $\mathrm{MPa}$ and $0.6 \mathrm{U} / \mathrm{h} / \mathrm{g} \mathrm{dm}$ for $-0.6 \mathrm{MPa})$ and control grains $(0.3$ $\mathrm{U} / \mathrm{h} / \mathrm{g} \mathrm{dm}$ ) (Figure 6A). After $120 \mathrm{~h}$ of sprouting, the observations were similar although the enzyme activity of the osmo-primed grains $(-0.3$ and $-0.6 \mathrm{MPa})$ no longer significantly differed from that of the control. The synthesis of endoxylanase can thus be accelerated by priming but does not necessarily lead to an increase in the total activity after 120 $\mathrm{h}$ of sprouting. The activity levels in grains primed at -1.2 $\mathrm{MPa}$ remained low with a maximum value of only $0.27 \mathrm{U} / \mathrm{h} / \mathrm{g}$ $\mathrm{dm}$ after $120 \mathrm{~h}$ of sprouting. Under such conditions, $\alpha$-amylase activity levels were also low (see 2.4). This confirms once more that a too low water potential during priming is detrimental to grain sprouting.

The increase in endoxylanase activity during sprouting corresponded with an increase in WEAX content from $0.48 \%$ of $\mathrm{dm}$ in non-sprouted control wheat to $0.98-1.34 \%$ of $\mathrm{dm}$ in (primed) wheat grains sprouted for $120 \mathrm{~h}$ (Figure 6). Indeed, endoxylanase converts water-unextractable AX into WEAX, thereby causing structural changes in cereal cell walls, ${ }^{22,45}$ which may be an indication of cell wall opening and hence nutrient release. Furthermore, soluble dietary fibers in particular (for example, WEAX) are one of the primary substrates for microbial fermentation in the human colon. ${ }^{46}$ Short-chain fatty acids as fermentation products can then promote colonic health by providing energy for the colonocytes and by decreasing gut permeability and motility. ${ }^{47}$ Finally, the degradation of AX is also of interest for maltsters and brewers since the incomplete degradation of dietary fiber components may result in high wort viscosity, causing filtration problems and, hence, reducing the extract yield after mashing. ${ }^{48}$

The WEAX contents for all treatments under study significantly increased with sprouting time. Prior hydropriming and osmo-priming led to significantly higher WEAX
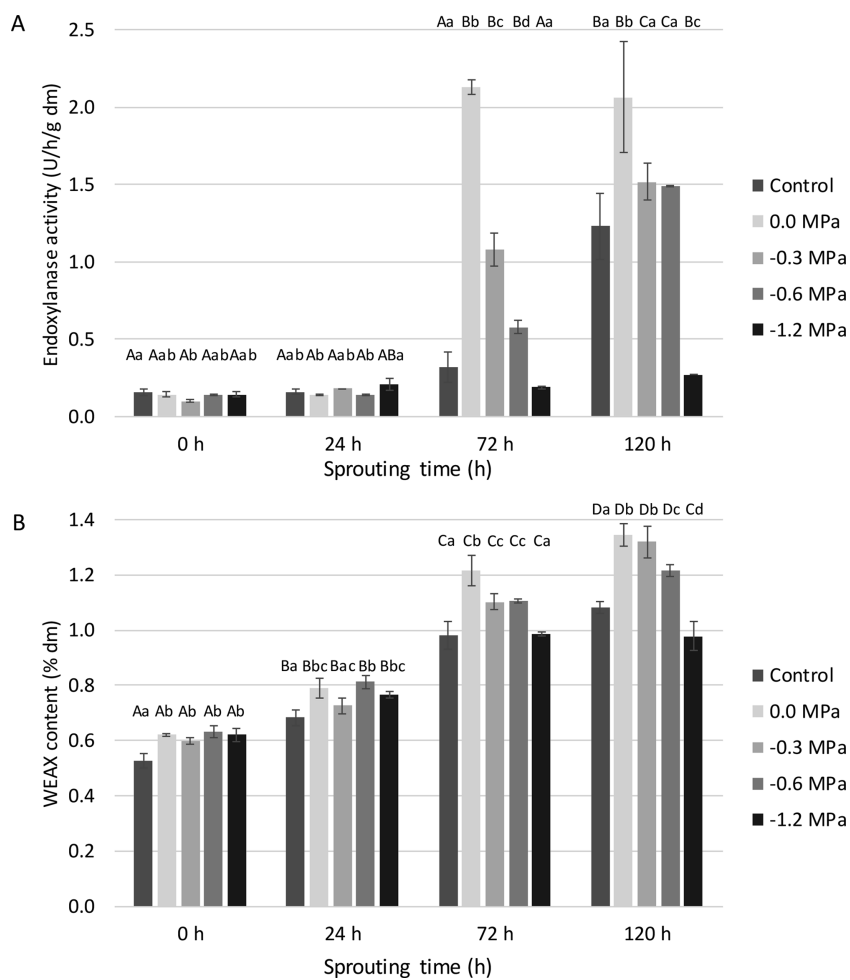

Figure 6. (A) Endoxylanase activity levels $(\mathrm{U} / \mathrm{h} / \mathrm{g} \mathrm{dm}$ ) and (B) water-extractable arabinoxylan (WEAX) contents (\% of $\mathrm{dm}$ ) as a function of sprouting time $(\mathrm{h})$ of non-primed (control), hydroprimed (0.0 MPa), and osmo-primed $(-0.3,-0.6$, and $-1.2 \mathrm{MPa})$ wheat grains (see pilot-scale experiment). Mean values for the same treatment differ significantly $(P<0.05)$ with those not sharing the same upper case letter. Mean values for the same sprouting time differ significantly $(P<0.05)$ with those not sharing the same lower case letter.

contents after steeping, confirming the grain's activated metabolism. The highest WEAX contents (1.32-1.34\% of $\mathrm{dm})$ were obtained in hydro-primed or osmo-primed $(-0.3$ $\mathrm{MPa}$ ) grains sprouted for $120 \mathrm{~h}$. The control grains and grains osmo-primed at $-1.2 \mathrm{MPa}$ contained lower WEAX contents $(0.98-1.08 \%$ of $\mathrm{dm})$ after 72 and $120 \mathrm{~h}$ of sprouting than did the other sprouted primed grains.

2.6. Impact of Hydro-Priming and Osmo-Priming on Phytase Activity Levels and Phytate Contents in (Sprouted) Wheat. The endogenous phytase activity level in non-sprouted control wheat corresponded to a release of 1.6 $\mu \mathrm{mol}$ phosphate $/ \mathrm{min} / \mathrm{g} \mathrm{dm}$. A significant increase in activity was found as a function of sprouting time. After $120 \mathrm{~h}$ of sprouting, it reached values of $8.1-9.3 \mu \mathrm{mol}$ phosphate $/ \mathrm{min} / \mathrm{g}$ $\mathrm{dm}$, depending on the priming treatment (Figure 7A). After steeping and after $24 \mathrm{~h}$ of sprouting, only hydro-primed grains showed 16 to $27 \%$ higher phytase activity levels than the other (primed) samples. Wheat itself contains a limited level of preformed inactive phytases, ${ }^{49}$ which may have been activated already during hydro-priming. Maybe impacting phase II of the germination process by priming does not impact phytase activity that much since the enzyme is first activated before it is de novo synthesized.

In this context, it is worth mentioning that Nasri et al. ${ }^{50}$ showed significant improvements in phytase activities in radicles, coleoptiles, and cotyledons of lettuce grains primed in $0.05 \%$ potassium nitrate at $25{ }^{\circ} \mathrm{C}$ for $2 \mathrm{~h}$. Increased 


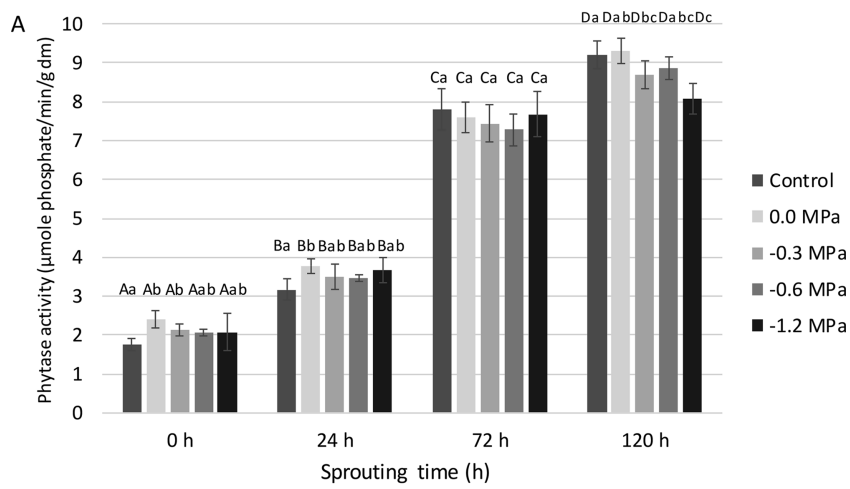

sprouting. Indeed, they can improve the nutritional properties (e.g., levels of bio-accessible nutrients, soluble dietary fiber, and intrinsic saccharides) of wheat whole grain food products. Moreover, this study offers opportunities for optimizing agricultural practice as well as industrial processes such as malting.

\section{MATERIALS AND METHODS}

3.1. Materials. All chemicals and reagents were of analytical grade and purchased from Sigma-Aldrich (Bornem, Belgium), unless otherwise specified. Wheat (Cellule winter wheat) was kindly supplied by Limagrain (Avelgem, Belgium).

3.2. Hydro-Priming or Osmo-Priming and Subse-

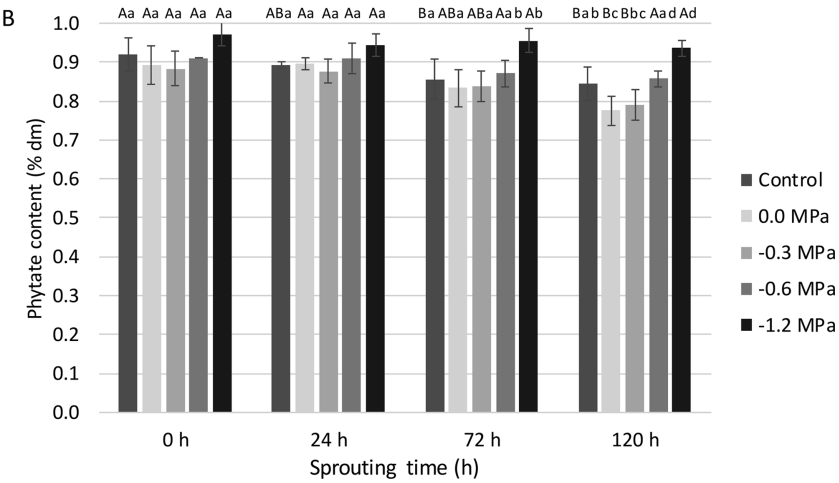

Figure 7. (A) Phytase activity levels $(\mu \mathrm{mol} / \mathrm{min} / \mathrm{g} \mathrm{dm}$ ) and (B) phytate contents $(\%$ of $\mathrm{dm})$ as a function of sprouting time $(\mathrm{h})$ of non-primed (control), hydro-primed $(0.0 \mathrm{MPa})$, and osmo-primed $(-0.3,-0.6$ and $-1.2 \mathrm{MPa})$ wheat grains (see pilot-scale experiment). Mean values for the same treatment differ significantly $(P<0.05)$ with those not sharing the same upper case letter. Mean values for the same sprouting time differ significantly $(P<0.05)$ with those not sharing the same lower case letter.

phosphatase activities may boost cell metabolism due to accelerated phosphate release and transport to support biosynthetic reactions in the growing embryo. ${ }^{50}$

Grains primed at $-1.2 \mathrm{MPa}$ showed $7-13 \%$ lower phytase activity levels than the other primed samples and control wheat after $120 \mathrm{~h}$ of sprouting, indicating a too high PEG concentration in the priming solution for optimal metabolic activity in the grains.

The 5- to 6-fold increase in phytase activity during sprouting corresponded with a decrease in phytate content from $0.96 \%$ of $\mathrm{dm}$ in non-sprouted control wheat to $0.94-0.78 \%$ of $\mathrm{dm}$ in (primed) wheat grains sprouted for $120 \mathrm{~h}$ (Figure 7B). Phytate concentrations in the control were significantly decreased after $72 \mathrm{~h}$ of sprouting, while they were only significantly decreased after $120 \mathrm{~h}$ of sprouting in hydro-primed and osmo-primed $(-0.3 \mathrm{MPa})$ grains. The highest phytate breakdown (19\%) was obtained in grains hydro-primed and subsequently sprouted for $120 \mathrm{~h}$. Osmo-priming at -0.6 or $-1.2 \mathrm{MPa}$ did not decrease phytate contents although the phytase levels were substantially increased. It may be that phytase action is limited in these grains due to the induced osmotic stress.

It seems that conditions more optimal for endogenous wheat phytase action $\left(\mathrm{pH} 4.0 ; 50{ }^{\circ} \mathrm{C}\right)$ are needed to hydrolyze phytate to a larger extent than noted here, and thus, to increase mineral bio-accessibility considerably more. ${ }^{24}$

In conclusion, this study shows that hydro-priming and, to a lesser extent, mild osmo-priming at a water potential of -0.3 $\mathrm{MPa}$ are powerful pretreatments of wheat grains prior to quent Sprouting of Wheat Grains on a Small-Scale. First, at least three samples of 25 grains were each put on a filter paper ( $90 \mathrm{~mm}$ diameter, Whatman filter, GE Healthcare Life Sciences, Buckinghamshire, UK) wetted with deionized water (hydro-priming; $0.0 \mathrm{MPa}$ ) or with polyethylene glycol (PEG 8000) solutions (osmo-priming) with water potentials of $-0.3,-0.6,-0.9,-1.2$, or $-1.8 \mathrm{MPa}$. The concentration of PEG needed to obtain the desired water potential was calculated using the formula presented by Michel: ${ }^{51}$

$$
\frac{\mathrm{g} \mathrm{PEG}}{\mathrm{g} \mathrm{H}_{2} \mathrm{O}}=\left[4-(5.16 \varphi T-560 \varphi+16)^{0.5}\right] /(2.58 T-280)
$$

with $\varphi$ representing the water potential (bar) and $T$ the temperature $\left({ }^{\circ} \mathrm{C}\right)$.

Next, these grains were incubated in a climate chamber with a day/night cycle of $12 \mathrm{~h}$ at $21{ }^{\circ} \mathrm{C}$, a light intensity of 120 $\mu \mathrm{mol} / \mathrm{m}^{2} \mathrm{~s}$ (white light from fluorescence lamps), and $70 \%$ relative humidity while monitoring their moisture content (see 3.4) and the germination percentage (see 3.4) over a $72 \mathrm{~h}$ time period.

3.3. Hydro-Priming or Osmo-Priming and Subsequent Steeping and Sprouting of Wheat Grains on a Pilot Scale. Based on the outcome of the above, grains (40.0 g) were hydro-primed at least in triplicate in deionized water $(0.0 \mathrm{MPa})$ or osmo-primed in PEG solutions $(300 \mathrm{~mL})$ with water potentials of $-0.3,-0.6$, or $-1.2 \mathrm{MPa}$ for $12 \mathrm{~h}$ at room temperature (RT) under gentle magnetic stirring. After osmopriming, the grains were washed three times for $5 \mathrm{~min}$ with deionized water to remove residual PEG from their surface. Afterward, they were oven-dried for $4 \mathrm{~h}$ at $40{ }^{\circ} \mathrm{C}$ and subsequently air-dried to reach a moisture content of $10-13 \%$ (i.e., about their initial moisture content).

Next, regular (control) and primed wheat grains were steeped and sprouted in a pilot-scale micromalting system (Joe White Malting Systems, Perth, Australia). The steeping process consisted of successive wet stages $\left(7,7\right.$, and $3 \mathrm{~h}$ at $\left.15^{\circ} \mathrm{C}\right)$ in a clear excess of deionized water and alternated by air rest stages ( 6 and $6 \mathrm{~h}$ at $15^{\circ} \mathrm{C}$ ). In a next step, the imbibed grains were sprouted for $120 \mathrm{~h}$ at $15{ }^{\circ} \mathrm{C}$. Samples were withdrawn after steeping and after 24,72 , and $120 \mathrm{~h}$ of sprouting. They were then flash-frozen with liquid $\mathrm{N}_{2}$ and used for determining the seedling characteristics (see 3.4) and plant hormone concentrations (see 3.5). For all other further analyses, the flash-frozen samples were freeze-dried.

3.4. Seedling Characteristics. The moisture content in grains was determined according to the AACC method 44$15.0^{52}$ in which the grains $(2.0 \mathrm{~g})$ are dried for $16 \mathrm{~h}$ at $130^{\circ} \mathrm{C}$.

For determining the percentage (\%) of germinated grains, a grain was considered to be germinated when its radicle had 
penetrated the surrounding structures and the white tip had become visible. For the small and pilot-scale experiment, 25 and 30 grains were used, respectively.

The growth of the seedlings was analyzed in sprouted (primed) wheat grains by measuring the lengths (in $\mathrm{mm}$ ) of the radicles and coleoptiles of 10 different grains with a digital calliper.

3.5. Plant Hormone Concentrations. 3.5.1. Auxins and Abscisic Acid. Wheat samples [100 mg taken from 10 flashfrozen, pooled, and magnalised grains (Retsch Mill MM200, Verder, Aartselaar, Belgium)] were extracted in triplicate in $800 \mu \mathrm{L}$ of $80 \%$ methanol. [ $\mathrm{C}^{13}$ ]-IAA [(phenyl- $\left.{ }^{13} \mathrm{C}_{6}\right)$-indole-3acetic acid, 99\%, Cambridge Isotopes, Tewksbury, MA, USA] and D-ABA $\left(\left[{ }^{2} \mathrm{H}_{6}\right](+)\right.$-cis, trans-abscisic acid, $\left[(S)-5-\left[{ }^{2} \mathrm{H}_{6}\right](1-\right.$ hydroxy-2,6,6-trimethyl-4-oxocyclohex-2-en-1-yl)-3-methyl$(2 Z, 4 E)$-pentadienoic acid], Olchemim, Olomouc, Czech Republic) were added as internal tracers (200 pmol of each).

After overnight extraction and subsequent centrifugation (20 min, 15,000g, $4{ }^{\circ} \mathrm{C}$, Eppendorf 5810R, Eppendorf, Hamburg, Germany), the supernatants were aliquoted in two equal parts.

One aliquot was acidified using $5.0 \mathrm{~mL}$ of $6.0 \%$ formic acid and concentrated on a reversed-phase (RP)-C18 cartridge (500 mg, BondElut Varian, Middelburg, The Netherlands). The compounds of interest [IAA, ABA, and the oxidation products IAA-OX, IAA-OH, indole-butyric acid (IBA)-OX, and IBA-OH] were eluted with $5.0 \mathrm{~mL}$ of diethyl ether and dried under nitrogen (TurboVap LV Evaporator, Zymark, New Boston, MA, USA).

The second aliquot was kept in $7.0 \mathrm{M} \mathrm{NaOH}$ for $3 \mathrm{~h}$ at 100 ${ }^{\circ} \mathrm{C}$ under a water-saturated nitrogen atmosphere to hydrolyze all ether and ester conjugates. ${ }^{53}$ Afterward, the samples were acidified using $2.0 \mathrm{M} \mathrm{HCl}$, concentrated on an RP-C18 cartridge $(500 \mathrm{mg})$, and eluted with diethyl ether as described before.

All samples were methylated using ethereal diazomethane ${ }^{54}$ to improve analysis sensitivity. Thus, all acid compounds were analyzed as their corresponding methyl esters. Samples were analyzed using an Acquity UPLC system linked to a TQD triple quadrupole detector (Waters, Milford, MA, USA) equipped with an electrospray interface in positive mode. Samples $(6.0 \mu \mathrm{L})$ were injected on an Acquity UPLC BEH C18 RP column $(1.7 \mu \mathrm{m}, 2.1 \times 50 \mathrm{~mm}$, Waters $)$ using a column temperature of $30{ }^{\circ} \mathrm{C}$ and eluted at $0.3 \mathrm{~mL} / \mathrm{min}$ with the following gradient of $0.01 \mathrm{M}$ ammonium acetate (solvent A) and methanol (solvent B): 0-2 min isocratic 90\% A, 10\% B; 2-4 min linear gradient to $10 \%$ A, $90 \%$ B. Quantification was done by multiple reactant monitoring of selected transitions based on the $\mathrm{MH}^{+}$ion (dwell time $0.02 \mathrm{~s}$ ) and the most appropriate compound-specific product ions in combination with the compound-specific cone and collision settings. All data were processed using Masslynx/Quanlynx software V4.1 (Waters).

3.5.2. Gibberellic Acid. Wheat samples ( $100 \mathrm{mg}$ taken from 10 flash-frozen, pooled, and magnalised grains) were extracted in triplicate overnight in $1.0 \mathrm{~mL}$ of acidified methanol $\mathrm{pH} 4.0$ [80/20, methanol/5.0 $\mathrm{mM}$ formic acid-containing butylated hydroxytoluene $(3-5$ crystals)]. As internal tracers, d2-GA1, d2-GA4, d2-GA8, d2-GA9, d2-GA15, d2-GA19, d2-GA20, and d2-GA29 (20 pmol each, Olchemim) were added. After purification on an RP-C18 cartridge (500 mg), samples were derivatized with $N$-(3-dimethylaminopropyl)- $N^{\prime}$-ethylcarbodiimide $\left(1.0 \mathrm{mg} / \mathrm{sample}\right.$, $\mathrm{pH} 4.0,60 \mathrm{~min}, 37{ }^{\circ} \mathrm{C}$ under continuous shaking, Eppendorf thermomixer). Next, these derivatized samples were analyzed using a UPLC-MS/MS equipped with an electrospray interface in positive mode (ACQUITY, TQD, Waters). Samples $(6.0 \mu \mathrm{L})$ were injected on an ACQUITY BEH C18 column $(2.1 \times 50 \mathrm{~mm} ; 1.7 \mathrm{~mm}$, Waters) using a column temperature of $30{ }^{\circ} \mathrm{C}$ and eluted at $450 \mu \mathrm{L} / \mathrm{min}$ with the following gradient of $0.1 \%$ formic acid in water (solvent $\mathrm{A}$ ) and $0.1 \%$ formic acid in acetonitrile (solvent B): $0-0.8 \mathrm{~min}$ isocratic $92 \% \mathrm{~A}, 8 \% \mathrm{~B} ; 0.8-5$ min linear gradient to $60 \% \mathrm{~A}, 40 \% \mathrm{~B} ; 5-5.5 \mathrm{~min}$ linear gradient to $10 \% \mathrm{~A}$, $90 \%$ B.

3.6. $\alpha$-Amylase Activity and Reducing Sugar Content. $\alpha$-Amylase activity was determined in triplicate with the amylazyme method (Megazyme, Bray, Ireland) as described in De Brier et al. ${ }^{55}$ but with slight modifications. A substrate tablet was added to $1.0 \mathrm{~mL}$ of a 5-50 times diluted preincubated extract from a whole meal of freeze-dried samples at $40{ }^{\circ} \mathrm{C}$, and the reaction was stopped after 5 to $120 \mathrm{~min}$ of incubation. Extract dilution and incubation time depended on the prior sprouting time. One $\alpha$-amylase unit (U) is defined as the enzyme activity per gram of $\mathrm{dm}$, which increases the extinction at $590 \mathrm{~nm}$ by 1.00 per $60 \mathrm{~min}$ of incubation at 40 ${ }^{\circ} \mathrm{C}$.

The reducing sugar content in a whole meal of freeze-dried samples was determined at least in triplicate as described by Moretti and Thorson ${ }^{56}$ but also with slight modifications. Prior to analysis, $\alpha$-amylase in the whole meal was inactivated by suspending an aliquot $(0.20-0.50 \mathrm{~g}$, depending on the time of sprouting) in $80 \%$ ethanol $(10.0 \mathrm{~mL})$ and evaporating the added ethanol at $95{ }^{\circ} \mathrm{C}$. The resulting whole meal was then suspended in $2.0 \mathrm{~mL}$ of deionized water, and the mixture was stirred for $20 \mathrm{~min}$ at 150 rotations per minute $(\mathrm{rpm})$ and $7{ }^{\circ} \mathrm{C}$. It was then centrifuged $\left(10 \mathrm{~min}, 4000 \mathrm{~g}, 20^{\circ} \mathrm{C}\right)$. An aliquot of the supernatant $(15 \mu \mathrm{L})$ was mixed with $1.50 \mathrm{~mL}$ of $p$ hydroxybenzoic acid hydrazide $(\mathrm{pOH}-\mathrm{BH})$ solution (i.e., 9:1 mixture of $0.50 \mathrm{M}$ sodium hydroxide and $5.0 \% \mathrm{w} / \mathrm{v}$ pOH-BH in $0.50 \mathrm{M}$ hydrochloric acid) and heated for $5 \mathrm{~min}$ at $100{ }^{\circ} \mathrm{C}$. After $10 \mathrm{~min}$ of cooling at RT, the extinction was measured at $410 \mathrm{~nm}$ and the concentration of reducing sugars in the extracts was determined using a calibration curve made with 0.0-5.0 mg maltose $/ \mathrm{mL}$. The reducing sugar content is expressed as milligrams of maltose equivalents (eq) per gram of $\mathrm{dm}$.

3.7. Endoxylanase Activity and Water-Extractable Arabinoxylan Content. Endoxylanase activity was determined at least in triplicate with the Xylazyme AX method (Megazyme) as described in De Brier et $\mathrm{al}^{55}$ with slight modifications. The enzymatic reaction was stopped after $6 \mathrm{~h}$ of incubation at $40{ }^{\circ} \mathrm{C}$. One endoxylanase $U$ is defined as the enzyme activity per gram of $\mathrm{dm}$, which increases the extinction at $590 \mathrm{~nm}$ by 1.00 per $60 \mathrm{~min}$ of incubation at $40{ }^{\circ} \mathrm{C}$.

Prior to determining the water-extractable arabinoxylan (WEAX) content at least in triplicate, endoxylanase was inactivated by suspending an aliquot $(0.334 \mathrm{~g})$ in $80 \%$ ethanol $(10.0 \mathrm{~mL})$ and evaporating the added ethanol at $95{ }^{\circ} \mathrm{C}$. The resulting whole meal was then suspended in $20.0 \mathrm{~mL}$ of deionized water, extracted (30 min, $\left.150 \mathrm{rpm}, 7{ }^{\circ} \mathrm{C}\right)$, and centrifuged $\left(10 \mathrm{~min}, 1500 \mathrm{~g}, 7^{\circ} \mathrm{C}\right.$ ) at least in triplicate. The WEAX in the supernatant was quantified by gas chromatography (Agilent 6890 Series, Santa Clara, CA, USA) as described by Loosveld et al. ${ }^{57}$ In essence, carbohydrates were converted to monosaccharides by acid hydrolysis with trifluoroacetic acid. Next, alditols were formed by reduction with sodium borohydride under alkaline conditions. Finally, 
the resulting alditols were derivatized to form alditol acetates using 1-methylimidazole as the catalyst. WEAX content was calculated as $0.88 \times$ the sum of xylose and arabinose contents.

3.8. Phytase Activity and Phytate Content. Phytase activity in an aliquot of a whole meal extract ( $\mathrm{pH}$ 5.0) was determined at least in triplicate based on the method of Heinonen and Lahti ${ }^{58}$ described in the study of Lemmens et al. ${ }^{24}$ Briefly, inorganic orthophosphate released from phytic acid is quantified colorimetrically $(400 \mathrm{~nm})$ using ammonium molybdate. One phytase $U$ is defined as the amount of enzyme that releases one micromole of phosphate per minute of incubation per gram of $\mathrm{dm}$ at $37{ }^{\circ} \mathrm{C}$ under the conditions of the assay.

The phytate content in the whole meal was determined at least in triplicate after acid extraction of myo-inositol phosphates following the procedure of the K-Phyt assay kit (Megazyme) as described by Lemmens et al. ${ }^{24}$ The concentration of free phosphates in the extracts was subtracted from the phosphate concentration after subsequent breakdown of myo-inositol phosphates by phytase and alkaline phosphatase. The phytate content was calculated by dividing that of bound phosphorus by 0.282 .

3.9. Statistical Analyses. Statistical analyses were conducted using the Statistical Analysis System software 14.0 (SAS Institute, Cary, NC, USA). One-way ANOVA with Tukey multiple comparison testing was used to verify whether mean values of responses under study were significantly $(P<$ 0.05 ) different.

\section{ASSOCIATED CONTENT}

\section{S Supporting Information}

The Supporting Information is available free of charge at https://pubs.acs.org/doi/10.1021/acsomega.9b03210.

Part of the gibberellic acid (GA) biosynthesis pathway mentioning the GA-oxidases (GA-ox) responsible for every conversion step (PDF)

\section{AUTHOR INFORMATION}

\section{Corresponding Author}

*E-mail: elien.lemmens1@kuleuven.be. Phone: (+32)-16374242. Fax: (+32)-16-321997.

\section{ORCID}

Elien Lemmens: 0000-0001-5220-8223

\section{Present Address}

"Present address: Centre for Evidence-Based Practice, Rode Kruis-Vlaanderen, Motstraat 42, 2800 Mechelen, Belgium

\section{Notes}

The authors declare no competing financial interest.

\section{ACKNOWLEDGMENTS}

This research was conducted in the framework of the W.K. Kellogg Chair in Cereal Science and Nutrition at the KU Leuven (chair holders J.A. Delcour and K. Verbeke) and is part of the Methusalem program "Food for the Future" (20072021).

\section{ABBREVIATIONS USED}

\section{ABA abscisic acid}

AX arabinoxylan

GA gibberellic acid

IAA indole acetic acid
IBA indole butyric acid

eq. equivalents

PEG polyethylene glycol

pOH-BH $p$-hydroxybenzoic acid hydrazide

rpm rotations per minute

RT room temperature

U unit

WEAX water-extractable arabinoxylan

\section{REFERENCES}

(1) Fincher, G. B. Molecular and cellular biology associated with endosperm mobilization in germinating cereal grains. Annu. Rev. Plant Physiol. Plant Mol. Biol. 1989, 40, 305-346.

(2) Bewley, J. D.; Bradford, K. J.; Hilhorst, H. W. M.; Nonogaki, H. Seeds: Physiology of Development, Germination and Dormancy; $3^{\text {rd }}$ ed., Springer: New York, USA, 2013, 1-399.

(3) Nonogaki, H.; Bassel, G. W.; Bewley, J. D. Germination - Still a mystery. Plant Sci. 2010, 179, 574-581.

(4) Lemmens, E.; Moroni, A. V.; Pagand, J.; Heirbaut, P.; Ritala, A.; Karlen, Y.; Lê, K.; Van den Broeck, H. C.; Brouns, F. J. P. H.; De Brier, N.; Delcour, J. A. Impact of cereal seed sprouting on its nutritional and technological properties: a critical review. Compr. Rev. Food Sci. Food Saf. 2019, 18, 305-328.

(5) Miransari, M.; Smith, D. L. Plant hormones and seed germination. Environ. Exp. Bot. 2014, 99, 110-121.

(6) Ma, Z.; Bykova, N. V.; Igamberdiev, A. U. Cell signaling mechanisms and metabolic regulation of germination and dormancy in barley seeds. Crop J. 2017, 5, 459-477.

(7) Di Girolamo, G.; Barbanti, L. Treatment conditions and biochemical processes influencing seed priming effectiveness. Ital. J. Agron. 2012, 7, 178-188.

(8) Ventura, L.; Donà, M.; Macovei, A.; Carbonera, D.; Buttafava, A.; Mondoni, A.; Rossi, G.; Balestrazzi, A. Understanding the molecular pathways associated with seed vigor. Plant Physiol. Biochem. 2012, 60, 196-206.

(9) Rehman, S.-U.; Khalil, S. K.; Khan, A. Z.; Subhan, F.; Younis, M.; Muhammad, Y.; Jan, N. Poly ethylene glycol (PEG) osmopriming affects phenology, plant height and biomass yield of rainfed wheat. SJA 2010, 26, 337-348.

(10) Khan, M. B.; Gurchani, M. A.; Freed, S.; Jabran, K.; Hussain, M. Osmopriming improves the emergence, growth, nutrient uptake and soluble sugar contents of wheat seedlings. Soil Environ. 2014, 33, $142-148$.

(11) Ghiyasi, M.; Siyahjani, A. A.; Tajbakhsh, M.; Amirnia, R.; Salehzadeh, H. Effect of osmopriming with polyethylene glycol (8000) on germination and seedling growth of wheat (Triticum aestivum L.) seeds under salt stress. Res. J. Biol. Sci. 2008, 3, 12491251.

(12) Salehzadeh, H.; Shishvan, M. I.; Ghiyasi, M.; Forouzin, F.; Siyahjani, A. A. Effect of seed priming on germination and seedling growth of wheat (Triticum aestivum L.). Res. J. Biol. Sci. 2009, 4, 629631.

(13) Yari, L.; Aghaalikani, M.; Khazaei, F. Effect of seed priming duration and temperature on seed germination behavior of bread wheat (Triticum aestivum L.). ARPN J. Agric. Biol. Sci. 2010, 5, 1-6. (14) Basra, S. M. A.; Farooq, M.; Tabassam, R.; Ahmad, N. Physiological and biochemical aspects of pre-sowing seed treatments in fine rice (Oryza sativa L.). Seed Sci. Technol. 2005, 33, 623-628.

(15) Hameed, A.; Sheikh, M. A.; Farooq, T.; Basra, S. M. A.; Jamil, A. Chitosan seed priming improves seed germination and seedling growth in wheat (Triticum aestivum L.) under osmotic stress induced by polyethylene glycol. Philipp. Agric. Sci. 2014, 97, 294-299.

(16) Paparella, S.; Araújo, S. S.; Rossi, G.; Wijayasinghe, M.; Carbonera, D.; Balestrazzi, A. Seed priming: state of the art and new perspectives. Plant Cell Rep. 2015, 34, 1281-1293.

(17) Mirza, S. R.; Ilyas, N.; Batool, N. Seed priming enhanced seed germination traits of wheat under water, salt and heat stress. Pure Appl. Biol. 2015, 4, 650-658. 
(18) Zhang, F.; Yu, J.; Johnston, C. R.; Wang, Y.; Zhu, K.; Lu, F.; Zhang, Z.; Zou, J. Seed priming with polyethylene glycol induces physiological changes in sorghum (Sorghum bicolor L. Moench) seedlings under suboptimal soil moisture environments. PLoS One 2015, 10, 1-15.

(19) Brocklehurst, P. A.; Dearman, J. Interactions between seed priming treatments and nine seed lots of carrot, celery and onion Ann. Appl. Biol. 1983, 102, 577-584.

(20) Hardegree, S. P. Drying and storage effects on germination of primed grass seeds. J. Range Manage. 1994, 47, 196-199.

(21) Toklu, F.; Baloch, F. S.; Karaköy, T.; Özkan, H. Effects of different priming applications on seed germination and some agromorphological characteristics of bread wheat (Triticum aestivum L.). Turk. J. Agric. For. 2015, 39, 1005-1013.

(22) De Backer, E.; Gebruers, K.; Van den Ende, W.; Courtin, C. M.; Delcour, J. A. Post-translational processing of $\beta$-D-xylanases and changes in extractability of arabinoxylans during wheat germination. Plant Physiol. Biochem. 2010, 48, 90-97.

(23) Raboy, V. myo-Inositol-1,2,3,4,5,6-hexakisphosphate. Phytochemistry 2003, 64, 1033-1043.

(24) Lemmens, E.; De Brier, N.; Spiers, K. M.; Ryan, C.; Garrevoet, J.; Falkenberg, G.; Goos, P.; Smolders, E.; Delcour, J. A. The impact of steeping, germination and hydrothermal processing of wheat (Triticum aestivum L.) grains on phytate hydrolysis and the distribution, speciation and bio-accessibility of iron and zinc elements. Food Chem. 2018, 264, 367-376.

(25) Amrein, T. M.; Gränicher, P.; Arrigoni, E.; Amadò, R. In vitro digestibility and colonic fermentability of aleurone isolated from wheat bran. LWT-Food Sci. Technol. 2003, 36, 451-460.

(26) Abbasdokht, $\mathrm{H}$. The effect of hydropriming and halopriming on germination and early growth stage of wheat (Triticum aestivum L.). Desert 2011, 16, 61-68.

(27) Almansouri, M.; Kinet, J.-M.; Lutts, S. Effect of salt and osmotic stresses on germination in durum wheat (Triticum durum Desf.). Plant Soil 2001, 231, 243-254.

(28) Abiri, R.; Shaharuddin, N. A.; Maziah, M.; Yusof, Z. N. B.; Atabaki, N.; Sahebi, M.; Azizi, P. Quantitative assessment of indica rice germination to hydropriming, hormonal priming and polyethylen glycol priming. Chil. J. Agr. Res. 2016, 76, 392-400.

(29) Ibrahim, E. A. Seed priming to alleviate salinity stress in germinating seeds. J. Plant Physiol. 2016, 192, 38-46.

(30) Lu, L.; Tian, S.; Liao, H. Z. J.; Yang, X.; Labavitch, J. M.; Chen, W. Analysis of metal element distributions in rice (Oryza sativa L.) seeds and relocation during germination based on X-ray fluorescence imaging of $\mathrm{Zn}, \mathrm{Fe}, \mathrm{K}, \mathrm{Ca}$ and $\mathrm{Mn}$. PLoS One 2013, 5, 1-9.

(31) Mousavi, S. R. Zinc in crop production and interaction with phosphorus. Aust. J. Basic Appl. Sci. 2011, 5, 1503-1509.

(32) Lemmens, E.; De Brier, N.; Spiers, K. M.; Garrevoet, J.; Falkenberg, G.; Smolders, E.; Delcour, J. A. Steeping and germination of wheat (Triticum aestivum L.). II. Changes in spatial distribution and speciation of iron and zinc elements using pearling, synchrotron X-ray fluorescence microscopy mapping and X-ray absorption near-edge structure imaging. J. Cereal Sci. 2019, 90, 102843.

(33) Jacobsen, J. V.; Pearce, D. W.; Poole, A. T.; Pharis, R. P.; Mander, L. N. Abscisic acid, phaseic acid and gibberellin contents associated with dormancy and germination in barley. Physiol. Plant. 2002, 115, 428-441.

(34) Finkelstein, R. R.; Gampala, S. S. L.; Rock, C. D. Abscisic acid signaling in seeds and seedlings. Plant Cell 2002, 14, 15-45.

(35) Yamada, K. Changes in the level of endogenous abscisic acid in barley during germination and use of abscisic acid in malting. J. Am. Soc. Brew. Chem. 1984, 42, 79-84.

(36) Kucera, B.; Cohn, M. A.; Leubner-Metzger, G. Plant hormone interactions during seed dormancy release and germination. Seed Sci. Res. 2005, 15, 281-307.

(37) Huang, Y.; Yang, W.; Pei, Z.; Guo, X.; Liu, D.; Sun, J.; Zhang, A. The genes for gibberellin biosynthesis in wheat. Funct. Integr. Genomics 2012, 12, 199-206.
(38) Appleford, N. E. J.; Evans, D. J.; Lenton, J. R.; Gaskin, P.; Croker, S. J.; Devos, K. M.; Phillips, A. L.; Hedden, P. Function and transcript analysis of gibberellin-biosynthetic enzymes in wheat. Planta 2006, 223, 568-582.

(39) Salazar-Cerezo, S.; Martínez-Montiel, N.; García-Sánchez, J.; Pérez-y-Terrón, R.; Martínez-Contreras, R. D. Gibberellin biosynthesis and metabolism: A convergent route for plants, fungi and bacteria. Microbiol. Res. 2018, 208, 85-98.

(40) Strader, L. C.; Culler, A. H.; Cohen, J. D.; Bartel, B. Conversion of endogenous indole-3-butyric acid to indole-3-acetic acid drives cell expansion in Arabidopsis seedlings. Plant Physiol. 2010, 153, 15771586.

(41) Zolman, B. K.; Yoder, A.; Bartel, B. Genetic analysis of indole3-butyric acid responses in Arabidopsis thaliana reveals four mutant classes. Genetics 2000, 156, 1323-1337.

(42) Duke, S. H. A comparison of barley malt amylolytic enzyme activities as indicators of malt sugar concentrations. J. Am. Soc. Brew. Chem. 2009, 67, 99-111.

(43) Jafar, M. Z.; Farooq, M.; Cheema, M. A.; Afzal, I.; Basra, S. M. A.; Wahid, M. A.; Aziz, T.; Shahid, M. Improving the performance of wheat by seed priming under saline conditions. J. Agron. Crop Sci. 2012, 198, 38-45.

(44) Farooq, M.; Barsa, S. M. A.; Wahid, A. Priming of field-sown rice seed enhances germination, seedling establishment, allometry and yield. Plant Growth Regul. 2006, 49, 285-294.

(45) Autio, K.; Simoinen, T.; Suortti, T.; Salmenkallio-Marttila, M.; Lassila, K.; Wilhelmson, A. Structural and enzymic changes in germinated barley and rye. J. Inst. Brew. 2001, 107, 19-25.

(46) Damen, B.; Verspreet, J.; Pollet, A.; Broekaert, W. F.; Delcour, J. A.; Courtin, C. M. Prebiotic effects and intestinal fermentation of cereal arabinoxylans and arabinoxylan oligosaccharides in rats depend strongly on their structural properties and joint presence. Mol. Nutr. Food Res. 2011, 55, 1862-1874.

(47) Bränning, C. E.; Nyman, M. E. Malt in combination with Lactobacillus rhamnosus increases concentrations of butyric acid in the distal colon and serum in rats compared with other barley products but decreases viable counts of cecal Bifidobacteria. JN 2011, 141, $101-107$.

(48) Sadosky, P.; Schwarz, P. B.; Horsley, R. D. Effect of arabinoxylans, $\beta$-glucans, and dextrins on the viscosity and membrane filterability of a beer model system. J. Am. Soc. Brew. Chem. 2002, 60, $153-162$.

(49) Ou, K.; Cheng, Y.; Xing, Y.; Lin, L.; Nout, R.; Liang, J. Phytase activity in brown rice during steeping and sprouting. J. Food Sci. Technol. 2011, 48, 598-603.

(50) Nasri, N.; Kaddour, R.; Mahmoudi, H.; Baatour, O.; Bouraoui, N.; Lachaâl, $M$. The effect of osmopriming on germination, seedling growth and phosphatase activities of lettuce under saline condition. Afr. J. Biotechnol. 2011, 10, 14366-14372.

(51) Michel, B. E. Evaluation of the water potentials of solutions of polyethylene glycol 8000 both in the absence and presence of other solutes. Plant Physiol. 1983, 72, 66-70.

(52) AACC. Method 44-15.02. Moisture -- Air-oven methods. In: Approved Methods of Analysis; AACC International: St. Paul, MN, USA, 1999.

(53) Bialek, K.; Cohen, J. D. Quantitation of Indoleacetic Acid Conjugates in Bean Seeds by Direct Tissue Hydrolysis. Plant Physiol. 1989, 90, 398-400.

(54) Schlenk, H.; Gellerman, J. L. Esterification of fatty acids with diazomethane on a small scale. Anal. Chem. 1960, 32, 1412-1414.

(55) De Brier, N.; Hemdane, S.; Dornez, E.; Gomand, S. V.; Delcour, J. A.; Courtin, C. M. Structure, chemical composition and enzymatic activities of pearlings and bran obtained from pearled wheat (Triticum aestivum L.) by roller milling. J. Cereal Sci. 2015, 62, 66-72.

(56) Moretti, R.; Thorson, J. S. A comparison of sugar indicators enables a universal high-throughput sugar-1-phosphate nucleotidyltransferase assay. Anal. Biochem. 2008, 377, 251-258. 
(57) Loosveld, A.-M. A.; Grobet, P. J.; Delcour, J. A. Contents and structural features of water-extractable arabinogalactan in wheat flour fractions. J. Agric. Food Chem. 1997, 45, 1998-2002.

(58) Heinonen, J. K.; Lahti, R. J. A new and convenient colorimetric determination of inorganic orthophosphate and its application to the assay of inorganic pyrophosphatase. Anal. Biochem. 1981, 113, 313317. 